\title{
Stan Brakhage, Maya Deren e Jonas Mekas: por uma poética do amateur
}

\section{Rafael Valles}

Doutor; Universidade Federal de Pelotas, Pelotas, RS, Brasil. ra.valles@hotmail.com

\section{Resumo}

Este artigo pretende analisar a questão do amateur no contexto do cinema de vanguarda norte-americano e de que forma as obras teóricas dos realizadores Stan Brakhage, Maya Deren e Jonas Mekas contribuíram para elaborar uma concepção poética sobre esse termo. A análise do tema será feita a partir dos seguintes textos: Amateur versus Profesional (Deren, 1959), In defense of amateur (Brakhage, 1971) e A linguagem mutante do cinema (Mekas, 1962). A metodologia estará centrada nos aspectos socioeconômico, artístico e técnico. $\mathrm{O}$ artigo defende a posição de que esses textos possuem uma importância histórica e teórica sobre o termo e contribuem para compreender a sua poética.

\section{Palavras-chave}

Cinema de Vanguarda Norte-americano. Amateur. Stan Brakhage. Maya Deren. Jonas Mekas.

\section{Introdução}

Delimitar o termo amateur e as questões que ele implica acaba possibilitando-nos uma diversidade de caminhos que estão relacionados tanto ao âmbito audiovisual, quanto fora dele. Se formos centrar esse tema somente nos registros audiovisuais, é preciso levar em conta práticas que abrangem desde registros caseiros, travelogues, vídeos experimentais, passando por propostas vanguardistas, até alcançar o contexto digital e a massificação de vídeos que são postados todos os dias nas redes sociais. Diante dessa 
diversidade de formas, pensar a questão do amateur é também um caminho para entender a pluralidade de sentidos que empregamos no uso dos dispositivos técnicos.

É necessário, no entanto, partir de um ponto essencial para ser compreendida a origem desse termo: a sua intenção não mercadológica. Como afirma Tepperman, no livro Amateur Cinema: the rise of North American moviemaking, 1923-1960:

A palavra amateur surgiu na língua Inglesa no final do século XVIII, emprestada da língua francesa: "Amateur, nas artes, é um termo estrangeiro que agora circula entre nós, empregado para denotar uma pessoa que entende e ama ou pratica as refinadas artes da pintura, escultura ou arquitetura, sem qualquer consideração de vantagem pecuniária". Essa desconsideração pela vantagem pecuniária diferencia o amateur de um trabalhador assalariado e sinaliza as origens aristocráticas das atividades amadoras (TEPPERMAN, 2015, p. 03, tradução nossa).

Ao estabelecer-se um sentido não mercadológico ao registro, também se insere uma questão socioeconômica que procura desvincular o uso desse termo de atividades que visam ao lucro financeiro. A definição do amateur está relacionada às condições de produção e à intenção que o autor assume em como decide registrar.

À medida que se trata fundamentalmente de uma relação econômica, o amateurismo acolhe qualquer prática não industrial exercida por razões distintas à dos intercâmbios mercantis. É a presença da mercantilização que define apropriadamente o industrial e, o contrário, a ausência de mercantilização é que define o amateur, mais do que as contingências históricas de suas respectivas tecnologias, estéticas ou ideologias. Assim, por ser uma prática não mercantilizada, o modo doméstico insere-se propriamente no campo do amateur, e suas funções culturais deveriam ser estudadas como relativamente autônomas (MORAN, 2010, p. 274-275, tradução nossa ).

Entendido isso, o objetivo deste trabalho não é abarcar toda a diversidade de formas que o amateur pode conter, mas como o uso desse termo foi fundamental para a construção de uma concepção poética ${ }^{1}$ relacionada ao cinema de vanguarda norte-americano ${ }^{2}$, a partir de três autores fundamentais a esse contexto: Maya Deren, Stan Brakhage e Jonas Mekas.

\footnotetext{
${ }^{1}$ Ao utilizar o termo "concepção poética", procuro abordar a forma como o autor concebe a sua obra, enquanto um "fazer criativo, uma poiesis". O termo grego poiesis aparece na obra aristotélica junto com a definição de tekné, cujo significado é saber fazer algo. Poiesis significa a realização de algo, criar alguma coisa, ação de produzir um objeto artístico, artesanal ou técnico a partir da aplicação do conhecimento prévio que nos oferta o saber como se faz, ou seja, a partir da aplicação da tekné correspondente" (CORTÉS, 2016, p. 26).

Disponível em: http://revistaseletronicas.pucrs.br/ojs/index.php/scriptorium/article/view/25125/15482
} 
Este trabalho analisará três textos que gravitam sobre a questão do amateur e que são bastante elucidativos sobre como os seus autores conceberam as suas obras fílmicas e as suas perspectivas teóricas sobre o cinema. Refiro-me a Amateur versus Profesional (Maya Deren, 1959), In defense of amateur (Stan Brakhage, 1971) e A linguagem mutante do cinema (Jonas Mekas, 1962).

A escolha desses três textos deve-se basicamente a dois pontos. 0 primeiro refere-se ao contexto em que os três autores escreveram tais textos. Todos coincidem com um momento de maturidade nas suas trajetórias. São reflexões de autores que já haviam construído um percurso no âmbito cinematográfico e artístico. Ao ser uma mescla de revisionismo com manifesto, Deren, Brakhage e Mekas buscaram teorizar o que já concebiam nas suas obras fílmicas.

Maya Deren escreveu o seu artigo quando já tinha 42 anos de idade. Nesse contexto, ela já havia produzido uma obra consolidada no âmbito do cinema vanguardista norteamericano e a sua obra teórica também já era reconhecida. 0 texto Amateur versus Profesional foi escrito dois anos antes de Deren falecer e quando ela já começava a se afastar do cinema para se dedicar aos estudos de cunho antropológico no Haiti.

No momento em que elaborou o texto In defense of amateur, Brakhage já vinha realizando filmes há pelo menos 19 anos $^{3}$ e encontrava-se com 38 anos de idade. Com uma obra fílmica que contém mais de 200 filmes - entre curtas, médias e longas -, Brakhage já era reconhecido como um dos pilares do cinema de vanguarda norte-americano. Sua obra bibliográfica também já se tornara um referencial teórico, a partir da publicação do livro Metaphors on Vision (1963) e de trabalhos que vinha elaborando no início da década de 1970, como é o caso de The Brakhage Lectures: Georges Méliès, David Wark Griffith, Carl Theodore Dreyer, Sergei Eisenstein (1972).

Quanto a Mekas, ele já tinha 40 anos de idade quando escreveu A linguagem mutante do cinema e vinha há sete anos dirigindo a Film Culture (revista referencial para o cinema de vanguarda, que ele criou e dirigiu em conjunto com o seu irmão Adolfas Mekas, no ano de 1955). A isso se soma a coluna semanal intitulada Movie Journal, que Mekas escrevia para o jornal nova-iorquino Village Voice, e que foi importante não somente para a construção de

\footnotetext{
${ }^{2}$ Ao empregar-se o termo vanguarda, assumo aqui a definição estabelecida por P. Adams Sitney no livro Visionary Film - the american avant-garde. Segundo Sitney, "os primeiros filmes americanos aqui discutidos foram chamados de poemas em filme ou filmes experimentais quando foram vistos pela primeira vez. Ambos os nomes, como todos os subsequentes, são imprecisos e limitados [...] Optei por usar o termo cinema de vanguarda ao longo do livro simplesmente porque é o único nome que não está associado a nenhuma fase específica do período de trinta anos que eu tento cobrir" (SITNEY, 1979 , p. vii-viii, tradução nossa).

3 Tendo em conta a realização do curta Interim (1952, 16mm, 26min.).
} 
um ponto de vista sobre o cinema, mas sobretudo pela defesa que ele fazia em torno de uma geração de realizadores que despontavam no cenário norte-americano nos anos sessenta.

O outro fator para escolher esses autores é o fato de que, além de serem referenciais para a construção do que hoje conhecemos como o cinema de vanguarda norte-americano do pós-guerra, também são artistas que se preocuparam com uma reflexão teórica sobre as suas concepções cinematográficas.

Maya Deren é considerada precursora da vanguarda norte-americana, sobretudo pelo que representa, neste contexto, o filme Meshes of the afternoon (1943), mas também pelas diversas conferências que realizou tanto nos Estados Unidos, como no Canadá e em Cuba, nas quais abordava a sua concepção poética e projetava fragmentos dos seus filmes. Deren também publicou livros como An Anagram of Ideas on Art, Form and Film (1946) e Divine Horsemen: Living Gods of Haiti (1953), que refletem as suas posições sobre o cinema, a relação com a dança e o sentido ritualístico que assumem ambos.

Brakhage tornou-se o nome referencial desta vanguarda não somente pela extensão da sua obra, mas sobretudo pela variedade de buscas poéticas que assumiu ao longo de 50 anos de atividade, indo desde "o psicodrama a princípio dos anos cinquenta até o lirismo autobiográfico" (BRAKHAGE, 2014, p.15, tradução nossa), com os registros caseiros sobre a sua vida íntima com a família nas montanhas no Colorado, até a abstração da imagem, com filmes feitos a partir de pinturas diretas sobre a superfície do material fílmico, sem o uso da câmera. Paralelamente a isso, além de ter escrito onze livros, ele também ministrou classes na School of the Art Institute de Chicago, foi professor distinguido de Estudos Cinematográficos na Universidade do Colorado, além de ter sido condecorado com três títulos honorários e numerosos prêmios (BRAKHAGE, 2014, p.16, tradução nossa). Como afirma Pablo Marin, "Brakhage recorre à escrita para, de alguma forma, desandar o caminho silenciosamente hermético do seu processo criativo cinematográfico" (BRAKHAGE, 2014, p. 19, tradução nossa).

Já a obra de Mekas tornou-se referencial para o que hoje entendemos como filmediário e pela escolha de fazer do registro do seu próprio cotidiano a busca por uma concepção poética na sua obra. Mas se, por um lado, ele não concebeu como teoria nem como crítica cinematográfica os textos que publicou na Film Culture e no Village Voice, por outro lado esses ensaios literários são fundamentais para entender como Mekas foi elaborando a sua visão sobre o cinema e como isso influenciou posteriormente os seus filmes-diário. 


\section{0 amateur como vanguarda}

É dentro desse contexto, relacionado à vanguarda e ao período pós-guerra, de que Deren, Brakhage e Mekas fazem parte, que se potencializa um novo tipo de vínculo do autor com a imagem. A escolha de registrar a sua própria intimidade, os momentos cotidianos da sua vida e, ao mesmo tempo, com isso, construir uma concepção poética sobre esse processo evidenciam uma perspectiva que problematiza a posição do autor.

Tanto a questão do diário fílmico como os registros de cunho autobiográfico já existiam antes mesmo do cinema no período pós-guerra ${ }^{4}$. No entanto, é na segunda metade do século XX que essa busca por filmes realizados em primeira pessoa se intensifica.

É importante lembrar que o desenvolvimento do cinema autobiográfico surgiu em um ponto específico dentro da história do cinema, envolvendo um processo de ruptura em que a poética da vanguarda foi conjugada com a adesão de técnicas "amadoras" como ferramentas artísticas para o retrato de si. O cinema autobiográfico não diz apenas "eu gostaria de contar a minha vida através do cinema," mas também "basta ao cinema como mídia de massa e como uma atividade industrial e coletiva". 0 cinema autobiográfico, portanto, foi concebido não como a história de qualquer vida, mas como a história da vida do artista. É uma expressão artística que mais ou menos autoconscientemente destaca o artista em sua resposta subjetiva a um ambiente e em seu interior simbólico (TURIM, 1992, p. 193, tradução nossa).

Ao afirmar a condição individual do artista, a "poética da vanguarda", as "técnicas amadoras" e um "basta ao cinema como mídia de massa", Turim opera um entrelaçamento de três fatores essenciais para a elaboração de um cinema autobiográfico e um entendimento sobre como a questão do amateur afirma uma relação com o cinema de vanguarda.

É preciso ressaltar que o período pós-guerra evidenciou a busca por formas artísticas que problematizam o próprio sentido de obra, uma vez que buscavam a ideia de processo. $\mathrm{O}$ autor procurava um sentido vivencial e inacabado aos trabalhos, criando assim

\footnotetext{
${ }^{4}$ Beauvais e Bouhours chegam a partir do pressuposto de que a origem do diário fílmico remonta aos primórdios do cinema com os irmãos Lumière, ao afirmarem que "a origem do diário filme remonta a do cinema, quando os irmãos Lumière capturam, para promover sua invenção, tanto o espaço público quanto o privado. Cenas de caráter íntimo ( $O$ Almoço do Bebê), cenas familiares e cotidianas ( $A$ Saída dos Operários das Usinas Lumière) ou imagens públicas (A Chegada do Trem na Estação de Ciotat). [...] Em um primeiro momento, essas gravações privilegiam o círculo familiar, o meio social, depois o ambiente cotidiano, como se o cinema despertasse para o mundo. Essa abertura ao mundo imiscui-se na expressão do eu: o eu subjetivo intervém nos fatos significando uma época” (BEAUVAIS; BOUHOURS, 1995, p. 1989, tradução nossa).
} 
uma zona difusa entre vida e arte, entre vivenciar uma experiência e narrá-la, num desejo de problematizar o sentido de representação, para buscar novas perspectivas poéticas.

Em todos os campos da arte americana do pós-guerra, o paradigma modernista estava sendo desafiado por assaltos a fronteiras entre gêneros, entre mídias, entre arte e não-arte, e entre arte e vida, e muitas vezes de uma forma que questionava o fetichismo do objeto de arte como mercadoria (JAMES, 1989, p. 98, tradução nossa).

Na busca do artista por evidenciar o processo de construção da sua obra, também se revela um sentido em fazer da sua esfera íntima e pessoal, parte integrante ou mesmo determinante na elaboração dos seus trabalhos. A afirmação da vanguarda no cinema norteamericano também passa por como o autor concebe um sentido autobiográfico aos seus trabalhos. $\mathrm{O}$ eu que se constrói nesse contexto é um eu concebido por artistas/cineastas que problematizam a própria concepção de registros caseiros - o que faz com que imagens de cunho familiar, que num primeiro momento restringiam-se à esfera privada do autor, assumam uma intenção artística. A concepção de filmes em primeira pessoa no cinema de vanguarda norte-americano começa a ser construída a partir do momento em que os registros caseiros tornam-se matéria-prima para a elaboração de obras fílmicas.

É surpreendente o número de cineastas que naquele momento se dedica a projetos autobiográficos e diarísticos: Stan Brakhage, Andrew Noren, Howard Guttenplan, Jerome Hill, Warren Sonbert, Hollis Frampton e Chantal Akerman. Esse fenômeno é contemporâneo ao que acontece no teatro, na dança e nas artes plásticas, em que práticas do cotidiano e experiências pessoais dos artistas passam a ser matéria para trabalhos. [...] Em todos eles entende-se o eu, ou a apreensão da vida, como um problema colocado à forma, um problema que questiona a forma, ou exige que ela seja tensionada (MOURÃO, 2013, p. 15).

Sobretudo na obra fílmica de Brakhage e Mekas, identifica-se um contexto em que filmar a si próprio e inserir esses registros na práxis da sua vida cotidiana foi um caminho para conceber outra perspectiva para o uso da câmera e a produção de imagens. "Não se trata apenas de fazer da vida assunto ou matéria de trabalho, mas diluir nela o próprio trabalho" (MOURÃO, 2013, p.15). É através da vanguarda cinematográfica norte-americana 
que a relação entre filmes de cunho autobiográfico, a premissa do cinema amateur e a utilização de registros caseiros acabam assumindo protagonismo.

\section{A construção de uma concepção poética}

A primeira questão que se identifica nos textos Amateur versus Profesional (Maya Deren, 1959), In defense of amateur (Stan Brakhage, 1971) e A linguagem mutante do cinema (Jonas Mekas, 1962) é a necessidade que os três autores apresentam de colocar os seus pontos de vista sobre a questão do amateur e/ou sobre a busca por um novo cinema. Ao elaborarem uma concepção sobre o cinema amateur, o que eles buscaram foi um entendimento sobre os aspectos socioeconômicos contidos na figura do amateur, do realizador.

Trago aqui três fragmentos dos textos selecionados, que são muito reveladores sobre como Deren, Brakhage e Mekas concebem o amateur no cinema. Segundo Deren,

o maior obstáculo para os cineastas amateurs é seu complexo de inferioridade em relação às produções profissionais. A classificação mesma de amateur tem uma conotação de desculpa. Mas essa mesma palavra - do latim amator, amante, refere-se a alguém que faz algo por amor e não por razões econômicas ou por necessidade [...]Em vez de invejar os enormes orçamentos de produção dos filmes profissionais com seus elaborados cenários, seus roteiristas, seus atores bem treinados e todo esse pessoal qualificado, o amateur deveria fazer uso de uma das maiores vantagens que tem e que todos os profissionais invejam dele, a chamada liberdade tanto artística como física! (DEREN, 2015, p. 177, tradução nossa).

Já Brakhage, logo no primeiro parágrafo do seu artigo assume um tom de depoimento, quando afirma:

Faço filmes há mais de quinze anos. Trabalhei em muitos filmes comerciais como diretor, diretor de fotografia, editor, roteirista, inclusive ator, etc. [...] Mas no geral, trabalhei sem títulos, sem colaborar com outras pessoas: trabalhei sozinho e na minha casa, em filmes sem valor comercial aparente... "em casa" com um meio que amo, fazendo filmes que quero e que me importam da mesma maneira que, como pai, amo aos meus filhos e me preocupo com eles. Como esses filmes caseiros estão sendo valorizados e têm desenvolvido uma vida pública, eu, seu criador, venho sendo chamado como um "profissional", um "artista" e um "amateur". Destes três 
termos, o último, "amateur", é o que mais me honra... Ainda quando seja o mais utilizado por pessoas que não entendem meu trabalho na hora de criticá-lo. (BRAKHAGE, 2014, p. 103, tradução nossa).

Quanto a Jonas Mekas, no artigo que publicou na sua coluna no Village Voice, ele não afirma o termo amateur, mas evoca filmes que têm esse perfil:

Mesmo os erros, os planos fora de foco, os planos tremidos, os passos inseguros, os movimentos hesitantes, os pedaços superexpostos ou subexpostos fazem parte do vocabulário. As portas para a espontaneidade se abrem; o ar viciado do profissionalismo rançoso e respeitável escapa. 0 que a velha geração esperta crê importante, o novo artista acha sem importância, pretensioso, entediante e, além do mais, imoral. Ele encontra mais vida e "importância" nos pequenos e insignificantes detalhes secundários. 0 insignificante, o efêmero, o espontâneo são as passagens que revelam a vida e que possuem todo o entusiasmo e a beleza. (MEKAS, 2013, p. 72).

Nos três fragmentos, existe uma intenção de defesa e de confrontação. Deren, Brakhage e Mekas defendem que a liberdade artística não se restrinja a padronizações ou poderes financeiros. Existe no amateur a ideia do "amante", de encarar o registro enquanto uma expressão desprendida da concepção do cinema como indústria, ou do realizador como um "profissional". Nesse entendimento, ocorre o que Laurence Allard define como "reivindicar certa identidade social e certa concepção de sua condição de realizador" (ALLARD, 2010, p. 262, tradução nossa), que acaba revelando "uma demonstração de independência socioeconômica da criação em relação aos meios de produção do cinema comercial narrativo" (ALLARD, 2010, p. 263, tradução nossa).

A defesa do amateur torna-se, assim, não somente um caminho de distinção ao "profissionalismo" do cinema, mas, sobretudo, uma busca de afirmação artística. Mais do que ser um diretor, no sentido de dirigir técnicos, atores e outros profissionais, o sentido empregado ao amateur diz respeito ao artista que se libera das convenções cinematográficas de decupagem, da elaboração de roteiro ou planejamentos financeiros de larga escala no trabalho de produção para, segundo as palavras de Deren, "dedicar-se a capturar a poesia e a beleza de lugares e acontecimentos" (DEREN, 2015, p. 177, tradução nossa). 
Não por acaso, esse entendimento sobre o amateur acabou se tornando fundamental para as concepções poéticas buscadas pelos três autores, nas suas respectivas obras. Deren, de alguma forma, buscava que o cinema saísse da dicotomia vigente naquela época entre ficção-entretenimento/documentário educativo, de filmes que transitavam entre os interesses comerciais dos grandes estúdios cinematográficos ou das organizações com fins educativos que realizavam filmes de não-ficção. Segundo ela, o que faltava era o "desenvolvimento do cinema como forma de arte, preocupado pelo tipo de percepção que caracteriza a toda disciplina artística [...] dedicado ao desenvolvimento de um idioma formal tão independente ao resto das formas artísticas" (DEREN, 2015, p. 67, tradução nossa).

É recorrente nos textos de Deren a sua intenção em procurar um caminho que liberasse o cinema das formas canônicas de produção. Tanto na sua obra fílmica, como no seu trabalho teórico, ela buscou na relação entre dança e cinema, entre o corpo e a câmera, uma forma de expandir a ideia de experiência dentro do registro das imagens em movimento. Trabalhos fílmicos que ela realizou - como é o caso de At land (1944), A Study in Choreography for Camera (1945), Ritual in Transfigured Time (1946) - são muito mais estudos, experiências que possibilitam refletir sobre a imagem fílmica, do que uma intenção de construir um filme, elaborar uma narrativa argumentativa.

Nesse sentido, a figura do amateur também vinha reivindicar um ideal de liberdade. Como ela afirma, "liberdade artística significa que o cineasta amateur nunca está forçado a sacrificar o drama visual e a beleza por uma corrente de palavras, palavras, palavras, por uma atividade frenética, pelas explicações de um argumento" (DEREN, 2015, p. 177, tradução nossa). A concepção que Deren busca no amateur está diretamente relacionada a um distanciamento do cinema argumentativo, vinculado a realizações como a dos filmes de estúdio hollywoodianos, por exemplo.

Já no que se refere à concepção do amateur segundo Stan Brakhage, ele traz no seu artigo um entendimento bastante claro sobre o termo, enquanto

[...] alguém que realmente vive sua vida - em vez de alguém que, simplesmente, "cumpre seu dever" - e, assim, experimenta seu trabalho à medida que o pratica - em vez de ir à escola e aprender seu trabalho para passar o resto da vida cumprindo seu dever. [...] É por isso que eu acredito que qualquer consideração do cinema como arte deve vir, inevitavelmente, do processo criativo amador do "filme caseiro". Penso, ainda, que o cinema "comercial" ou ritual deve também, inevitavelmente, seguir as pegadas dos 
filmes amadores em vez do contrário, como comumente acontece hoje em dia. (BRAKHAGE, 2014, p. 105,110, tradução nossa).

0 ato de "viver a sua vida, sem cumprir deveres" e a ideia de "experimentar seu trabalho à medida que o pratica", possuem um sentido fundamental na obra de Brakhage, uma vez que a sua obra não somente se afirma nos registros de acontecimentos cotidianos seus e da sua família, mas também de uma concepção poética que se constrói a partir dos registros dessas práticas cotidianas. Quando Brakhage afirma que o cinema "comercial" deve seguir as pegadas dos filmes amadores, na verdade procura afirmar que "o cineasta amateur filma pessoas, lugares e objetos que ama e os eventos felizes e de importância pessoal, num gesto que atua direta e unicamente de acordo as necessidades da memória" enquanto que o cinema dito "comercial", personificado por Hollywood, "constrói dramas ritualísticos como celebração da memória das massas - de maneira similar aos rituais das tribos - e filmes idealistas com o objetivo de controlar o destino nacional" (BRAKHAGE, 2014, p. 109, tradução nossa).

Nessa relação, existe um desejo, por parte de Brakhage, de voltar um olhar ao singular, ao gesto pessoal de filmar indivíduos, lugares e objetos, distanciando-se, assim, do que o autor define como "uma pseudoigreja cujo 'deus' é a 'psicologia das massas'” (BRAKHAGE, 2014, p. 109, tradução nossa). Assim como afirma Deren, Brakhage também evoca aqui a liberdade do amateur, a possibilidade que ele sempre tem de se desvencilhar de todo o aparato industrial contido no cinema de cunho comercial, para assim afirmar a sua singularidade. Como ele próprio afirma, "em todas as dimensões criativas sou guiado principalmente pelo espírito da casa que habito, por minha própria sala de estar" (BRAKHAGE, 2014, p. 110, tradução nossa).

Desse modo, ele fez filmes em que registra o parto do seu filho (Window water baby moving, 1959), a sua relação com a passagem do tempo e com Jane (Wedlock house: an intercourse, 1959) e Marilyn, respectivamente, sua primeira e segunda esposa. Brakhage encontrou, num entendimento sobre a figura do amateur, uma forma para conceber a sua própria obra fílmica.

Rejeitando o trabalho alienado da carreira industrial, onde a lida com o cinema só poderia, na melhor das hipóteses, ter financiado uma vida fora dela, a inovação fundamental de Brakhage estava na esfera da produção. Quando seu projeto era lido em meros termos de estilo ou assunto, como filmes à parte o cinema que implicavam, os filmes eram inevitavelmente 
mal interpretados, de maneira hedionda, é claro, como pornografia. Ao tornar-se um amateur - alguém que, conforme um trocadilho favorito, fazia aquilo por Amor e não por Dinheiro - ele transformou a cinematografia na agência do seu próprio ser. Ligando o estético e o existencial, o cinema passou a ser identificado com sua vida e a coincidir com ela, a ser ao mesmo tempo sua vocação e avocação, seu trabalho e divertimento, sua alegria e terror - tão fundamental quanto o ato de respirar. (JAMES, 1989, p. 36-37, tradução nossa)

Já no que se refere a Jonas Mekas, o registro cotidiano da sua vida também evoca a sua própria condição de exílio, depois de refugiado - a situação em que chegou aos Estados Unidos, num contexto relacionado ao fim da Segunda Guerra Mundial. Só que, para pensar a questão do amateur a partir da perspectiva de Mekas, também é necessária uma contextualização sobre as influências que ele incorporou no contexto norte-americano, nos anos 1960. Entre a sua vinda aos Estados Unidos, em 1949, até a finalização de Walden - seu primeiro filme-diário - vinte anos depois, muitos fatores demarcaram a construção da sua concepção poética.

Do advento da literatura beat, em meados dos anos 1950, passando pelas projeções do Cinema $16^{5}$, referencial sala de cinema nova-iorquina que projetava filmes experimentais e de vanguarda, até uma posição central que o cenário artístico norte-americano ${ }^{6}$ assumiu no contexto pós-guerra, relacionado ao cinema de vanguarda. Esses são apenas alguns dos fatores que somaram referenciais artísticos para Mekas ir construindo tanto a sua obra fílmica quanto a sua produção teórica.

Tanto os textos que escreveu ao longo dos anos 1950 e 1960, na sua coluna Movie Journal e na revista Film Culture, como as imagens que registrou por meio do seu diário fílmico evidenciam o quanto a pulsão vanguardista desse período assumiu uma forte influência na sua trajetória cinematográfica. Existe, assim, uma relação intrínseca entre a consciência de Mekas quanto à forma do seu diário fílmico, a figura do amateur e o contexto

\footnotetext{
${ }^{5}$ Em entrevista realizada por Scott MacDonald no dia 24 de maio de 1985 e publicada no livro Cinema 16 - Documents Toward a History of a Film Society, ele diz para Jonas Mekas: "Lembro-me de você me dizer que começou a ir às sessões do Cinema 16 assim que chegou no país". Mekas assim respondeu: "Sim, ele era muito famoso naquela época. Domingo de manhã era o Cinema 16 - das onze horas até não sei quando, no teatro Paris e depois no Central Needle Trades Auditorium. Nós (Jonas e seu irmão Adolfas) nos juntamos imediatamente e participamos de todas as sessões do Cinema 16. Por algum tempo, foi o único lugar onde se podia ver o cinema de vanguarda americano. Afetou a minha vida toda, é claro; considero-o uma das minhas universidades". (MACDONALD, Scott. Cinema 16 - Documents Toward a History of a Film Society, 2002, tradução nossa).

${ }^{6}$ É importante ter em conta o trabalho de contextualização que P. Adams Sitney procura realizar sobre esse período, ao afirmar que "nos anos 40, duas consequências da Segunda Guerra Mundial contribuíram para a revitalização do cinema norteamericano de vanguarda. Muitas das principais figuras da vanguarda europeia buscaram refúgio nos Estados Unidos. Deren jogava xadrez habitualmente com Marcel Duchamp. Hans Richter lecionava Cinema em Nova York, onde tanto Buñuel como Salvador Dali já estavam estabelecidos. Man Ray e Oskar Fischinger estavam em Los Angeles. Além disso, nos armazéns do exército e com os Marines podiam se achar, a baixo custo, equipamentos de $16 \mathrm{~mm}$ e restos de filmes vencidos." (SITNEY, 2012, p. 1264, tradução nossa)
} 
do cinema de vanguarda norte-americano.

Como no início dos anos 60 Mekas abandonou gradualmente sua esperança de um cinema narrativo reformado e moldado a partir das novas ondas europeias, o trabalho de filmagem amador adquiriu para ele um novo status. Os tipos de infrações associados a isto passaram a ser reconhecidos como um vocabulário plenamente articulado com implicações éticas intrínsecas: vislumbres da vida cotidiana se tornaram mais importantes do que ficções de narrativa abrangente; uma imagem "lírica" fragmentária, insubstancial e imperfeita era preferida em lugar de uma imagem realista, completa e consciente da própria presença; e o equipamento rudimentar de 16 ou $8 \mathrm{~mm}$ passou a ser mais valorizado do que o aparato de estúdio. (JAMES, 2013, p. 178-179)

Em palestra proferida no dia 26 de agosto de 1972, Mekas comentou justamente sobre essas transformações na sua forma de conceber os seus registros fílmicos e de que forma o cinema de vanguarda e as técnicas relacionadas ao cinema amateur influenciaram a realização dos seus filmes-diário.

O desafio agora é capturar aquela realidade, aquele detalhe, aquele fragmento físico bem objetivo da maneira mais próxima possível de como meu Eu está vendo. Claro, o que enfrentava era o velho problema de todos os artistas: fundir a Realidade e o Eu, e produzir uma terceira coisa. Tinha de libertar a câmera do tripé e adotar todas as técnicas e processos cinematográficos subjetivos que já estavam disponíveis ou que acabavam de surgir. Tratava-se de uma aceitação e de um reconhecimento das conquistas do cinema de vanguarda dos últimos 50 anos. Isso afetou o tempo de exposição, movimentos, ritmo, tudo. Tive de descartar as noções acadêmicas de exposição "normal", movimento "normal", normal e apropriado isso, normal e apropriado aquilo. Tive de me inserir, de me fundir com a realidade que estava filmando por meio do ritmo, iluminação, exposições, movimentos (MEKAS, 2013, p. 134).

Ao "libertar a câmera do tripé e adotar todas as técnicas e processos cinematográficos subjetivos", assim como "descartar as noções acadêmicas de exposição 'normal', movimento 'normal'”, Mekas operou rupturas em relação as suas concepções prévias relacionadas à realização cinematográfica ${ }^{7}$

\footnotetext{
${ }^{7}$ No artigo "O filme-diário", Mekas comenta que os primeiros registros do seu diário fílmico tinham a intenção de praticar, mais do que construir uma obra com as imagens que procurou integrar à práxis da sua vida cotidiana: "Eu estava me preparando, ou tentando manter o contato com a minha câmera, de modo que, quando chegasse o dia em que tivesse tempo, faria então um filme 'de verdade'”. (MEKAS, 2013, p. 131)
} 
Seus artigos publicados no jornal Village Voice entram assim em consonância com as posições assumidas por Maya Deren e Stan Brakhage, na medida em que buscam sedimentar a posição de que "o cinema foi liberado do 'regime' de Hollywood. 0 realizador está livre das técnicas 'profissionais', dos temas de Hollywood, das rotinas de argumento, da iluminação de Hollywood" (MEKAS, 2016, p. 193, tradução nossa). Ao mesmo tempo em que Mekas propunha-se a tornar-se defensor de uma perspectiva cinematográfica relacionada ao amateur, foi esse contexto que também lhe trouxe elementos para conceber o filme-diário como parte fundamental na sua obra.

Por último, é importante ressaltar também a influência que a escolha dos dispositivos técnicos assumiu na construção de uma concepção poética relacionada ao amateur, no contexto do cinema de vanguarda norte-americano. A questão técnica assume protagonismo nesse âmbito, já que Deren, Brakhage e Mekas pertencem a um período em que o surgimento de câmeras mais leves e com maior agilidade para o seu manuseio foi fundamental para a busca por um cinema mais pessoal, íntimo. As fronteiras entre o amateur, o artista e o cineasta tornam-se cada vez mais tênues através de câmeras portáteis de $8 \mathrm{~mm}$ e $16 \mathrm{~mm}$.

Deren afirma em seu artigo que "graças ao seu equipamento pequeno e ágil que possui uma discreta mobilidade física, o cineasta amateur acaba provocando inveja na maioria dos profissionais que estão sob pressão pelas suas toneladas de monstros, cabos e equipamentos" (DEREN, 2015, p. 178, tradução nossa). Mais adiante, no último parágrafo desse breve artigo de duas páginas, ela também afirma: "a parte mais importante do seu equipamento é você mesmo, seu corpo móvel, sua mente criativa, e sua liberdade para usar ambos" (DEREN, 2015, p. 178, tradução nossa).

Já Brakhage afirma, em seu artigo, uma relação cotidiana que tem com o dispositivo técnico:

Levo comigo uma câmera (geralmente de $8 \mathrm{~mm}$ ) cada vez que saio de casa (ainda quando vou ao armazém) e assim me transformo num turista camarógrafo do meu entorno imediato e daqueles lugares mais distantes que visito (muitas das câmeras de $8 \mathrm{~mm}$ cabem com facilidade numa sacola). (BRAKHAGE, 2014, p. 110, tradução nossa).

Trata-se de um período em que começam a popularizar-se as câmeras portáteis, e autores como Deren, Brakhage e Mekas exaltam as potencialidades desses dispositivos para a busca por um outro cinema. "Está chegando o dia em que os filmes amadores em 8mm 
serão colecionados e apreciados como uma bela arte popular, como as canções e a poesia lírica que foram criadas pelo povo", escreveu Mekas em 1963, em outro artigo para o Village Voice, intitulado "Cinema em $8 \mathrm{~mm}$ como arte popular".

Esses três autores não estavam falando somente sobre câmeras Super 8, Bolex $16 \mathrm{~mm}$ ou tantos outros dispositivos técnicos. Estavam falando sobre como atribuímos sentidos poéticos a esses dispositivos. A popularização desses suportes não somente possibilitou uma produção em massa de registros caseiros, filmes familiares, mas também contribuiu para ampliar um entendimento sobre o uso do termo amateur. Nessa fusão entre arte/vida, o registro fílmico como construção de uma experiência que se insere no cotidiano do autor, Deren, Brakhage e Mekas procuraram problematizar, pela figura do amateur, o que concebemos ou não como arte.

\section{Considerações finais}

Passados mais de quarenta anos desde a publicação desses textos, o que temos a partir deles são testemunhos de uma época que hoje pertence à história do cinema e das vanguardas cinematográficas. No entanto, não é somente isso. São textos que procuram entender a importância da figura do amateur e de uma forma de conceber o cinema. Um entendimento sobre o amateur passa pela análise que esses três autores realizaram tanto na práxis fílmica, como nas suas respectivas obras teóricas.

Diante de um contexto atual tomado pelo protagonismo das redes sociais, com o uso de dispositivos técnicos cada vez mais leves e ágeis e com a relação cada vez mais tênue entre ser um artista, um profissional e/ou um amateur, esses textos trazem-nos uma perspectiva histórica e poética para pensar o uso desse termo. Brakhage, Deren e Mekas buscaram refletir sobre três pontos fundamentais que abarcam a questão do amateur: o fator socioeconômico, o artístico e o técnico.

No que se refere ao aspecto socioeconômico, os textos aqui analisados tornaram-se manifestos contra o sentido da obra de arte como mercadoria, contra um cinema que visa à produção e ao consumo em massa. Ao evocarem a figura do amateur como um amante, como alguém que realiza a sua arte sem o compromisso do retorno financeiro, Brakhage, Deren e Mekas buscaram o ideal da liberdade criativa, a realização de um trabalho que não 
está atrelado à forma industrial de produção que constitui os cinemas de estúdio hollywoodianos.

Ao assumirem essas posições, os três autores também reivindicam uma arte que procura, na experimentação do uso da linguagem e no registro cotidiano de imagens caseiras, uma intenção poética que afirma uma outra forma de experiência imagética. Tanto nas suas obras fílmicas como nas suas produções teóricas, Brakhage, Deren e Mekas reivindicaram registros fílmicos que confrontam um sentido narrativo do cinema. Ao assumirem uma zona limiar na relação entre arte/vida, arte e não arte, assim como o cruzamento entre diferentes gêneros e mídias, eles também se tornaram fundamentais para o entendimento do que hoje conhecemos como o cinema de vanguarda norte-americano. Mesmo não sendo um movimento - devido à diversidade de autores e concepções poéticas que compõem esse cenário vanguardista entre os anos 1950 e 1970- ainda assim é possível identificar uma recorrência desses realizadores em buscarem um sentido mais lírico e fragmentário à imagem.

Outro fator importante contido na questão do amateur refere-se ao seu aspecto técnico. Brakhage, Deren e Mekas reivindicaram não somente o uso de equipamentos mais rudimentares, mas também uma intenção poética contida nessas limitações técnicas. É por meio desses dispositivos técnicos rechaçados pelo cinema dos estúdios que também se acentuava um entendimento do amateur a partir da sua liberdade criativa. Esses autores encontraram nas câmeras portáteis um caminho para construírem obras de cunho mais íntimo, pessoal, autobiográfico. Tanto nas suas obras fílmicas como nos seus textos teóricos, eles procuraram mostrar que mesmo as falhas técnicas, os planos fora de foco e o uso da câmera na mão potencializavam as técnicas amadoras como ferramentas artísticas.

É importante entender que, mais do que alcançar uma definição, o que se buscou neste artigo foi identificar a construção de uma concepção poética, composta por autores que abordaram a questão do amateur a partir de uma perspectiva prática e teórica. Os filmes e textos de Brakhage, Deren e Mekas procuraram evidenciar nessa questão a relação tênue que se constrói entre arte e vida, entre o real e a criação, assim como a construção de um gesto que evoca a liberdade de criação e confronta a ideia da arte como mercadoria. 


\section{Referências}

ALLARD, Laurence. Un encuentro entre el cine doméstico y el experimental: el cine personal. In: ÁLVAREZ, Efrén Cuevas (org.). La casa abierta: el cine doméstico y sus reciclajes contemporáneos. Madrid: Ocho y Medio, Libros de Cine, 2010. p. 255-271.

BEAUVAIS, Yann; BOUHOURS, Jean-Michel. Le Je à la caméra. In: BEAUVAIS, Yann; BOUHOURS, Jean-Michel. Le Je Filmé. Paris: Éditions du Centre Pompidou, 1995. p. 19891977.

BRAKHAGE, Stan. En defensa de lo amateur. In: BRAKHAGE, Stan. Por un arte de la visión: Escritos esenciales. Buenos Aires: EDUNTREF, 2014. p. 103-111.

CORTÉS, Olga Nancy Peña. A criação poética na perspectiva de Paul Valéry. Scriptorium, Porto Alegre, v. 2, n. 1, p. 22-31, jan./jun. 2016.

DEREN, Maya. Amateur versus Profesional. In: DEREN, Maya. El universo Dereniano:textos fundamentales de la cineasta Maya Deren. Cuenca: Ediciones de la Universidad de CastillaLa Mancha, 2015. p. 177-178.

DEREN, Maya. El cine como forma de arte. In: DEREN, Maya. El universo Dereniano: textos fundamentales de la cineasta Maya Deren. Cuenca-Espanha: Ediciones de la Universidad de Castilla-La Mancha, 2015. p. 67-78.

JAMES, David E. Allegories of cinema: American Film in the Sixties. New Jersey: Princeton University Press, 1989.

JAMES, David. Diário em filme/ Filme-diário: prática e produto em Walden, de Jonas Mekas. In: MEKAS, Jonas; MOURÃO, Patrícia (org.). Jonas Mekas. São Paulo: Centro Cultural Banco do Brasil - USP, 2013. p. 165-205.

MACDONALD, Scott. Cinema 16 - Documents Toward a History of a Film Society. Philadelphia: Temple University Press, 2002.

MARIN, Pablo. Por un arte de la vision, por una visión del arte de Stan Brakhage. In: BRAKHAGE, Stan. Por un arte de la visión - Escritos esenciales. Buenos Aires: EDUNTREF, 2014. p. 17-24.

MEKAS, Jonas. A linguagem mutante do cinema. In: MOURÃO, Patricia (org.). Jonas Mekas. São Paulo: Centro Cultural Banco do Brasil; Pró-reitoria de Cultura e Extensão Universitária - USP, 2013. p. 70-73

MEKAS, Jonas. Cinema em 8mm como arte popular. In: MEKAS, Jonas; MOURÃO, Patrícia (org.). Jonas Mekas. São Paulo: Centro Cultural Banco do Brasil; Pró-reitoria de Cultura e Extensão Universitária - USP, 2013. p. 78. 
MEKAS, Jonas. 0 filme-diário. In: MEKAS, Jonas; MOURÃO, Patrícia (org.). Jonas Mekas. São Paulo: Centro Cultural Banco do Brasil; Pró-reitoria de Cultura e Extensão Universitária USP, 2013. p. 131-142.

MORAN, James M. Cine domestico, amateur y de vanguardia: modos de distinción. In: ÁLVAREZ, Efrén Cuevas (org.). La casa abierta: el cine doméstico y sus reciclajes contemporáneos. Madrid: Ocho y Medio, Libros de Cine, 2010. p. 273-299.

MOURÃO, Patrícia. Salve Jonas. In: MOURÃO, Patrícia; MEKAS, Jonas. (org.). Jonas Mekas. São Paulo: Centro Cultural Banco do Brasil; Pró-Reitoria de Cultura e Extensão Universitária - USP, 2013. p. 11-27.

SITNEY, P. Adams. El cine de vanguardia. In: BRUNETTA, Gian Piero. Historia mundial del cine. Madrid: Ediciones Akal, 2012. p. 1259-1284.

SITNEY, P. Adams. Visionary film: the american avant-garde. Nova Iorque: Oxford University Press, 1979.

TEPPERMAN, Charles. Amateur cinema: the rise of North American moviemaking, 19231960. Oakland: University of California Press, 2015.

TURIM, Maureen. Reminiscences, Subjectivities, and Truths. In: JAMES, David. To free the cinema: Jonas Mekas and the New York Underground. Princeton, New Jersey: Princeton University Press, 1992. p. 193-212.

\title{
Stan Brakhage, Maya Deren and Jonas Mekas: towards a poetics of the amateur
}

\begin{abstract}
This article will analyze the question of the amateur within the context of North-American avant-garde cinema, and the way in which the theoretical work of directors Stan Brakhage, Maya Deren and Jonas Mekas has contributed for the elaboration of a poetics of this term. The analysis of this theme will be grounded on the following texts: Amateur Versus Professional (Deren, 1959), In Defense of Amateur (Brakhage, 1971), and The Changing Language of Cinema (Mekas, 1962). Our study will focus on the following aspects: socioeconomic, artistic, and technical. The article defends the position that these texts have a historical and theoretical importance on the term and contribute to understand its poetics.
\end{abstract}

\section{Keywords}

American Avant-garde Cinema. Amateur. Stan Brakhage. Maya Deren. Jonas Mekas. 
Stan Brakhage, Maya Deren e Jonas Mekas: por uma poética do amateur

Recebido em 15/05/2019

Aceito em 01/07/2019 